\title{
Evolutionary Thermodynamics and Theory of Social Quality as Links between Physics, Biology, and the Human Sciences
}

Jaap Westbroek, Harry Nijhuis, and Laurent van der Maesen

\begin{abstract}
This article seeks to open a dialogue between physics, other natural sciences, and the human sciences. Part 1 questions time reversibility as a fundament of physics. This runs counter to the discourses of all other sciences, which do presume the irreversibility of time and the evolution of phenomena. Characteristics of evolution (time irreversibility, chance, evolvement of higher levels of organization) are explained according to the laws of thermodynamics. Evolutionary thermodynamics (ET) is launched as a new connecting concept. Part 2 explores interpretation of the human sciences in analogy with ET. Dialectical interaction between levels of organizational complexity is seen as a driving force in the evolution of nature, humans, and societies. The theory of social quality and the social quality approach (SQA) imply ontological (and epistemological) features with close affinity to elements of ET. Therefore, the SQA carries potentialities to stimulate border-crossing dialogue between the sciences.
\end{abstract}

Keywords: coherence, dialectic, entropy, evolution, organizational level, social quality, thermodynamics, time reversibility

Physics, through its original relationship to astronomy, has always been seen as the mother of all modern sciences, including the other natural sciences and subsequent human sciences. It holds itself to be the only science truly capable of uncovering truth about reality in mathematical formulas. Because the ontology of physics is grounded on the reversibility of time, it is able to reproduce experimental research without the influence of events in time. All other sciences, however, are based on ontologies that assume both the irreversibility of time (difference between past and future) and the presence of increasing levels of organization (evolution). Their research subjects and their contexts can—and do-change over time. Their experiments are therefore not perfectly reproducible. The conclusion is then an assumption that the other sciences are unable to explain the truth about reality. Laws of evolution cannot be explained by 
fundamental physical laws and are therefore presumed to be of lower quality. Both the ontologies and the epistemologies of the evolutionary sciences are considered secondary to those of physics. This largely explains why many sciences try to stay as close as possible to the essentials of physics. Many scientific approaches base their ontologies on causal relationships between specific parts (determinism, atomism). Larger wholes and their interdependent relationships with smaller constituent parts are often not included in these ontologies. This implicitly leads to epistemological approaches in which these relationships between parts are measured with quantitative methodologies. It is with such approaches that they most resemble the laws of physics and thereby hope to garner similar scientific authority.

Part 1 of this article seeks to bridge the fundamental laws of physics and ontologies based on the time-irreversible evolution of natural phenomena. The argument regarding ET (evolutionary thermodynamics) is largely based on evolutionary phenomena in biology. It begins with questioning the time reversibility of Newton's laws. According to these laws, no evolution would be possible. The second law of thermodynamics, however, does imply the possibility of the irreversibility of time. The discrepancy between Newton's laws and the second law of thermodynamics is explained. In order to interpret this incongruity on a deeper level, the philosophical perspectives of René Descartes and Baruch Spinoza (founders of ontological thinking on the workings of nature) are considered. The second law is reinterpreted to explain the possibility of the increase of complexities ("evolution") in nature as studied in all the sciences, except physics.

The concept of ET is introduced as a unifying ontological concept. It hypothesizes that the local evolvement of dynamic higher levels of order (complexities) is possible through newly identified faces of the second law. ET is then shown to possess the potentiality to eliminate the discrepancy identified above. The workings of chance and the dynamic evolvement of coherent levels of organization are explained as elements inherent in ET. Evolutionary processes take place dialectically, whereby interdependent cooperation between levels of complexities constitutes the potentiality to resist the leveling effect of entropy maximization or, in other words, the loss of order.

Biology was the first of the sciences to develop an evolutionary vision and has a rich tradition of exposing and explaining the nature of evolutionary processes in living nature. Biology is also a pars pro toto for other sciences. Astronomy, for example, which enjoyed enormous development alongside physics, is today based on evolutionary thinking. The ET concept, which reasons according to fundamental laws of physics, possesses the potential to link the evolutionary natural sciences with the physical sciences.

Part 2 of this article presents reflections about what insights the ET concept offers for the ontological and epistemological approaches of the human sciences. The interpretation of the history of human scientific discourses reveals four distinct ground patterns of ontology and associated epistemologies. Indeed, today's research methodologies in the human sciences tend to stay as close as possible to positivist experimental 
approaches as dictated by physics and its claims of truth. We take a closer look at this tendency.

In our discussion of ET - in accordance with Spinoza - the evolutions of humans and societies are considered as phenomena of Nature as a unity. Particular attention is given to the interdependent dialectical character of processes in societies between humans and (evolving) levels of societal organization. We propose that the theory of social quality, both in ontological and epistemological terms, represents a framework that shows close affinity with ET. It is based on an elaborated dialectical ontology, and, in an epistemological sense, has been built to develop comprehensive knowledge of humans and societies. Social quality theory has the potential to explain human phenomena and evolution according to dialectical processes. Like ET, it offers us an opportunity to link knowledge about living and non-living nature and human societies. We refer here to the theory of social quality as the social quality approach (SQA).

As potential catalysts for connecting the sciences, both ET and the SQA seek to end the theoretical and practical divide between physics and other natural and human sciences. The dialogue between these traditionally fragmented disciplines can be facilitated by the links offered by ET and SQA. Such a dialogue is a great deal more than just an exercise, more than art for art's sake. It is an absolute prerequisite to being able to comprehensively understand and address the challenge of the sustainability of human existence on earth. The persistent and ongoing scientific divide has intensely frustrated comprehensive the visions, politics, and policies needed to realize this sustainability.

\section{Part 1: Evolutionary Thermodynamics (ET) and Physics}

\section{Time Reversibility in Physics}

Modern physics originated in the sixteenth and seventeenth centuries. Isaac Newton was the first to record the general laws of dynamics in mathematical formulas (Newton 1687). His three natural laws constitute the foundation of the paradigm of physics: (1) an object set in motion by a force will persist in that motion; (2) action and reaction are equal but opposite; and (3) masses attract each other (the law of universal gravitation). In the centuries since Newton, physics research has focused on explaining —in a similar mathematical way—other physical phenomena. James Clerk Maxwell (1831-1879) determined a number of natural laws governing electricity and magnetism. Later, in the twentieth century, Newton's physics was questioned by Albert Einstein and Niels Bohr, who established yet more fundamental laws in mathematical formulas. Einstein, put simply, showed that Newton's physics no longer held true in the macrocosm, where space seems to merge in time. Bohr showed that the microcosm does not have a gradual transition from one micro-situation to another, but that this is accompanied by leaps. 
In the ensuing course of human history, physics has been continuously expanding (Cohen 2007). With Newton's laws, a new step had been taken. The philosophical foundation for his ontology was formulated in the rationalism of René Descartes, which primarily states that nature should be understood in terms of mathematical logic. His goal was "to make philosophy a kind of universal mathematics, a science in which everything is derived from simple basic concepts through rigorous deduction" (Störig 1959: 4.2). In this way, philosophy and physics merged. Today, the description of reality in mathematical terms still constitutes the foundation of modern physics. Newton saw himself primarily as a philosopher, and physics continues to be viewed as the science with the strongest connection to philosophy.

Time reversibility (action $=-/$ - reaction) is a fundamental concept of the ontology of physics. This applies to Newton's physics, as well as to the theories of relativity and quantum mechanics. The mathematical equations of theoretical physics allow no place for irreversible changes in time. Theoretically, reality is consequently fully determined, and the future is fully predictable. In the late 1700s, this ontology led to Pierre-Simon de Laplace's well-known statement: "A thinking mind that, at a given moment, would know all the laws of nature and also the state of all things that make up the world, would, if it were intelligent enough to analyze these data, clearly envisage both the past and the future" (De Laplace 1886: 7.6-7).

The reversibility of time as an ontological principle gives physical science a strong epistemological position in endeavors to uncover truth about reality. It presumes the possibility of the absolute reproducibility of experimental research. The outcome of an experiment that is not predicted can only be explained because the theory to be tested is not true. Following this epistemological procedure, a theory can only definitively be falsified by an experiment (Popper 1934).

In fact, the respect and authority that physics has accrued over the centuries, with its presumption of objective scientific research, reaches very far indeed. Other sciences continue to pay great homage to physics as the leading example in many ontological and epistemological respects. Implicitly or explicitly, linear mechanistic (deterministic) thinking forms the foundation of many of the modern sciences. In their respective searches for truth—by means of reproducible experiments and statistics—all sciences in fact try to approach objective evidence as dictated by physics.

\section{Time Irreversibility in Evolutionary Sciences}

Biology emerged as a modern science in the sixteenth and seventeenth centuries. Just as there is a strong connection between physics and astronomy, there is a strong connection between biology and such sciences as medicine and geology. The core of biological ontology was described by Charles Darwin. Its principles, though, had already been formulated by Jean-Baptiste Lamarck and others (Lamarck 1809). Biology holds that the organization of organisms in living nature increases over time. By evolving higher levels of organization, new species are created with better chances of survival. 
A giraffe with a longer neck can eat the leaves of a higher tree and therefore increases its chances of survival. Lamarck explained this by saying that a new characteristic is the result of an organism adapting to a new environment. This characteristic is then inherited. Darwin (1859) stated that organisms with hereditary traits that provide better adaptation to the new environment are most likely to have (many) offspring. Darwin's laws of evolution laid the foundation for the further development of biology, just as Newton's did for modern physics. Biology is based on an inherently and fundamentally different ontology than physics. There is a lasting difference between past and future, and the complexity of life increases over time. Biological ontology is founded on the irreversibility of time.

With the sole exception of physics, this time-irreversible ontology is entirely consistent with all other sciences, including the human and social sciences. All are based on permanent differences between past and future and on increasing complexity. Even astronomy, which is so strongly linked to the physical paradigm, no longer limits its investigation of the universe- as was the case with Johannes Kepler, Galileo Galilei, and Newton - to the solar system, where the sun rises independently of time every day. Instead, today's astronomy looks at the continuous evolution of the universe on a different space and time scale. Steven Weinberg describes how this began in the first three minutes after the Big Bang (Weinberg 1979). The Dutch physicist Erik Verlinde even thinks that gravity evolved immediately after the Big Bang. He thereby makes Newton's law itself part of an evolutionary process (Verlinde 2011). The evolution of the universe evolves in steps. First, the elements hydrogen and helium are formed, then later the other elements are formed, and then the first molecules appear (Reeves 1981). Evolution was in place from the birth of the Earth and continues to unfold through history, through nonliving and living nature, mankind and society. It is evident from all these examples that an increase in complex order takes place. It would seem a logical impossibility that the universe could be built according to the laws of physics, which state that time is reversible.

The epistemology of biology is quite different from that of physics. Because study subjects and their contexts change over time, scientific studies can never be precisely reproduced. Theories in search of truth can therefore-following Popperian procedures-never be definitely falsified. Truths about living nature are approached as closely as possible by employing theoretical plausibility and statistical methodologies, which try to maximize the chance that the truth is uncovered. Nonetheless, biology has developed into a highly productive and authoritative science, notwithstanding its deviation from the principles of physics. It moreover does not have the same relationship to philosophy as physics does. Descartes — with his rationalist philosophy-is not seen as its philosophical founder. Nor can biology use mathematical formulas to fundamentally explain reality. Biology limits itself to explanations of living nature and makes no statements about nonliving nature. 


\section{Descartes and Spinoza: Two Ontologies of Nature}

One must question whether or not the fundamentally different ontologies of physics and biology can exist alongside one another. This question is here interpreted in the light of two original philosophical ontologies about the workings of nature.

The ontological view of biology, with its time irreversibility, is in essence not contrary to Cartesian philosophy, from which physics was born. Descartes's understanding of God is important in this. René Descartes (1596-1650) stated that God is outside everything and that God created two substances: mind and body. These substances each have their own attributes: the mind has "thinking" as an attribute; the body has "extensiveness" (matter). Everything that determines nature comes from God and thus has a transcendent cause. To this end, it is God that possesses the conatus ("endeavor," "striving"). God decides to create nature on the basis of the conatus, but God can also continually intervene in nature. For Descartes, therefore, nature was not a unity that must eternally be subject to the same laws. Based on Descartes's concept of God, it was quite possible that completely different laws applied to living nature than to physical nature. On the basis of this rationalist Cartesian philosophy, physics and biology could be explained by different sets of mutually exclusive laws. It is from this perspective that these two sciences have been able to coexist for centuries. It appears that there has never been any common scientific discourse to interpret this incongruence of time reversibility versus time irreversibility. The different approaches to the concept of time were simply not a problem.

The contradiction between the two discourses, however, came to light in Spinoza's philosophical approach to Nature. For the most part, Baruch Spinoza (1632-1677) adopted Descartes's system of thought, although he was the first philosopher to disagree with Descartes's notion of God. Spinoza introduced fundamental changes to some essential elements of Cartesian philosophy. He held that there are not two substances (mind and body), but only one: God or Nature (Deus sive Natura) (Spinoza 1678). God and Nature are one, referred to as "substance." Mind (thought) and matter (extension) are attributes of this single substance. Everything that is - matter, living nature, man and society (even the thinking of Spinoza himself) — is Nature. Nature is consequently responsible for its own development: Natura naturans ("Nature makes Nature") and Natura naturata ("Nature becomes Nature"). Nature is no longer created by a transcendental God, but realizes itself. All phenomena of Nature logically have an immanent cause, which is present in Nature. All natural laws originate from Nature itself. Nature is a unity, and its fundamental laws are valid everywhere and at all times. From this Spinozan perspective, biology and physics must then have a common ontological basis with universally coherent governing laws.

This raises the fundamental question at the basis of our argument. Can an ontology of the universe be based on two diametrically opposed theories of time? For Descartes, this would be possible because of the intervention of his transcendental God. For Spinoza, it was indeed not possible. For him, everything was Nature and Nature is 
a unity. For Spinoza, Nature itself was responsible for time. All modern sciences, without exception and in line with Spinozan thought, have abandoned the idea that the transcendental God of Descartes creates the fundamental laws from outside nature. Gregor Mendel's (1822-1884) genetic laws do not come from God. They stem from the natural processes in which heredity is organized in higher organisms. They have a cause immanent to nature. So do Newton's laws.

In the ontological patterns of astronomy, geology, biology, and the human sciences, the reversibility and irreversibility of time are not observed side by side. In these sciences, there is only time-irreversible evolution. The occurrence in nature of the two different ontologies (of biology and physics) therefore becomes a logical impossibility. This discrepancy needs to be resolved. Spinozan ontology becomes the logical starting point for developing an argument that can lead to dissolving the discrepancy. This argument aims to formulate a theory that is able to link the laws of physics and the laws of evolutionary biology. In this, the primacy of fundamental physical laws is respected. Biology will here be used as a heuristic example of an evolutionary science in order to illustrate the argument.

\section{Thermodynamics and the Formation of Order}

Thermodynamics came into being in the nineteenth century as a branch of physics. It evolved not as a philosophical, but as a pragmatic engineering science, from investigations into the lack of efficiency of steam engines. It is consequently first and foremost associated with chemistry and engineering. For physics, it is only relatively important, although both Hendrik Lorentz and Albert Einstein gave it considerable attention. In his 1977 Lectures on Physics, Richard Feynman said: "we will not use thermodynamics very much in this course. Thermodynamics is used very often by engineers and, particularly, by chemists. So we must learn our thermodynamics in practice in chemistry or engineering." (Feynman 1977: I, 44, 12). Nonetheless, in the decades since, research into black holes has in fact meant that thermodynamics has suddenly played an important role in theoretical physics.

The first and second laws of thermodynamics constitute the cornerstone of thermodynamic theory. Like Newton's laws, they are fundamental to physics. It is essential to note that both of these laws are researched in isolated systems of energy transition. In open systems — as we will see below— the laws are also applicable, though their workings are more complicated to identify. The first law (the conservation of energy) posits that at every energy transition, the amount of energy before and after the transition, is equal. If it were only this law that was at issue, time would be reversible. The second law of thermodynamics says that the quality of energy after an energy transition is lower than before the transition. This lower-quality energy often consists of heat. In a moving car, the energy contained in the gasoline is converted into kinetic energy and heat. The first law states that the energy contained in gasoline is as large as the sum of kinetic energy and heat energy. The second law says that the heat energy that 
is produced is of lower quality. It is important to note here that this process of energy transition in reality is irreversible. Another example is a drop of ink in a beaker of water. At first, the water is still clear, except where the ink drop ended up, which is dark blue in color. The drop of ink gradually spreads through the water until all the water becomes light blue in color. In reality, this process is likewise irreversible.

Rudolf Clausius (1865) introduced the concept of entropy as a measure of the amount of loss of quality of energy. The second law then implies that, in an isolated system, entropy increases at each energy transition, until a maximum is reached. The ink dissolves completely in the water and the entropy is then maximized. The ink particles are still moving, but at the micro level, producing a new, balanced situation, with equal amounts of ink particles moving in and out. The fluid maintains the same color, and there is no more change. Entropic death has occurred. Entropy increase means loss of order: when the drop of ink landed in the beaker, there was a certain degree of order. A certain degree of information was organized in the system: in one place it contained ink, in another place it did not. When the ink completely dissolved, that information was lost.

So, the second law says that entropy can only increase and subsequently order can only decrease. In this regard, Richard Feynman postulated a fundamental statement: "The two laws of thermodynamics are often stated this way: First law: the energy of the universe is always constant. Second law: the entropy of the universe is always increasing" (Feynman 1977: I, 44, 12). For Feynman, there was no source of energy from outside the universe (the God of Descartes). Spinoza took the same position: there is nothing outside Nature, and the universe is an isolated system. This means that only a reinterpretation of thermodynamics can explain the formation of order and the evolution of nature.

A heuristic example from biology in which order formation occurs in an isolated system may clarify the reinterpretation of the second law. The folding of a protein in a cell can illustrate the order formation in an isolated system. A protein consists of a long chain of different amino acids. It originates as different amino acids bond together in a biochemical process in the aqueous environment of the cell. Water molecules are bound to the amino acids by hydrogen bonds. The bound water-unlike the water of the aqueous environment-possesses order (information). When the amino acids bond to each other, water molecules are pressed out of the forming protein, and internal hydrogen bonds are formed between the various amino acids. The water molecules pressed out of the evolving protein then lose their information. Entropy within the system increases. But the internal hydrogen bonds cause the protein to fold and assume a three-dimensional structure. At specifically the local level within the cell, the order (information) increases and the entropy decreases. According to the second law of thermodynamics, this entropy decrease — as a result of the protein-folding -is smaller than the entropy increase of the whole system.

The entropy maximization in the isolated system as a whole remains the law. If this were not the case, then energy of higher quality would be generated out of nothing. 
The local entropy decreasing in the context of a larger isolated system of entropy increase appears to be an essential addition to the second law of thermodynamics. In addition to producing disorder, the second law also appears to be capable of explaining the creation of order. This phenomenon is observed in all evolutionary processes taking place in the universe. The creation of a star is another example of a comparable order-forming process in nonliving nature.

In this regard, it is essential to note that the energy added from outside in open systems is only supporting local order formation. The two faces of the second law remain responsible for the organization of order. That external energy, however, plays an important role because it reinforces the energy intensity and speed of order-forming processes. Ilya Prigogine has done considerable research on this (Prigogine 1980). In open systems, many situations of reinforced order formation and evolution are to be observed. The Earth is such an open thermodynamic system: solar energy is continuously being added into it. Biological evolution of species is another example, as was the Industrial Revolution, which required a great deal of energy from outside the industrial systems themselves. In these evolutionary situations, energy added from outside is supporting the reinforcement of the formation of order.

\section{Evolutionary Thermodynamics (ET)}

Formation of order, complexity, or information is a secondary phenomenon of the law of entropy maximization. The second law of thermodynamics indeed has two faces. On the one hand, it explains the disappearance of information in the whole system. On the other, it explains that local order can arise at the same time. This new interpretation of the second law is referred to as evolutionary thermodynamics (ET). It explains - as an aspect of physical ontology — the laws that govern the evolution of living and nonliving nature. Within the ET concept, the evolution of the solar system, the elements, the Earth, molecules, proteins, living beings, humans, and society is based on the local ordering potentiality of the second law of thermodynamics. All these evolutions acquire a fundamental physical explanation.

How are these physical phenomena of entropy maximization and reduction interpreted according to the laws of biological evolution? Darwin described the influence of the environment on biological entities. Pressures from the environment ensure that the entity that is best able to resist these pressures has the best chance of producing offspring (evolution). These pressures from the environment in living nature can be interpreted as the pressures of entropy maximization according the workings of the second law. The local order that arises with the folding of the protein in the process of organizing complexity is in fact local entropy reduction. The evolutionary process over time is the continuous organization of local entropy reduction, which takes place under the pressure of entropy maximization in the system as a whole. This new interpretation explains that, over time, order can be produced as an irreversible phenomenon. In evolutionary terms, in certain places and at specific times in living and 
nonliving nature, order, over time, is evolving in levels of increasing organization. In these evolutionary phenomena, biology, astronomy, and geology, as well as the human and social sciences, have their vested scientific interests.

In biology, a clear distinction is made between "evolution" and "emergence." In the case of emergence, nothing new needs to be developed. With every egg from which a chick hatches, there is emergence. But with the first hatched chick, the development of this new complex phenomenon is referred to as evolution. Evolution goes beyond emergence. The entropy-lowering effect of the second law can achieve evolution as well as emergence. Since Darwin, evolution has been claimed as a matter concerning living nature. With ET, evolution becomes a fundament of nature as a whole. The distinction that biology makes between emergence and evolution is therefore applicable to all other phenomena in the universe.

Darwin postulated that evolution is based on mutations caused by accidental changes in organisms. These changes do occur by chance. Magnified and evolved under pressure of the environment, changes may eventually lead to new species. In case, by chance, a new amino acid enters the chain of amino acids at a certain place in the protein, this can have major consequences. The three-dimensional shape of the protein is changed. Usually, the cell will not be able to do anything with this new protein. The leveling effect of the entropy maximization will break it down. But occasionally, the new protein has an interesting new function for the system of the cell. This can sometimes be the starting point for a total change of the organism. Apparently, the relative stability of the mutation is then sufficient to make this change functional. In ET terms: with local entropy reduction, the protein regularly organizes itself-by chance-in slightly different ways. In almost all cases, this protein will be degraded by the leveling action (entropy maximization) of the second law. In rare cases, this new order develops the potential to arm itself against the leveling effect of the entropy maximization. The new protein will then be functional for the levels of organization above it.

A new level of organization is created in time by the workings of chance. Chance makes the course of the evolution basically unpredictable. The Big Bang had an indefinable future. It can only be explained in hindsight. The elements of hydrogen and helium were not yet present. Nature did not "know" that the carbon atom would be capable of making larger molecules such as proteins, DNA, or sugars. The protein was not "known" to be able to perform that specific function for the cell. Evolution is not a determined process. This applied to nonliving phenomena, and-later in evolutionto living phenomena. In particular, this holds true for the evolutionary phenomena and processes concerning man and society. In other words, ET also explains how-according to the laws of physics - processes of evolution are unpredictable because of chance. Deterministic laws of physics, as described by De Laplace, which theoretically hypothesize the ultimate predictability of phenomena in the universe, are not in accordance with the ET explanation of the laws of thermodynamics. 


\section{Dialectic between Levels of Organization as Evolutionary Force}

Evolution may be considered as the continuous formation of ever new coherent levels of organization, which are interdependent for their survival. Prigogine (1980) was the first to analyze this phenomenon. The physicist Leonard Susskind (2019) likewise states that nature has an order of levels of organization. Molecules are composed of atoms, with each atom consisting of a nucleus with electrons revolving around it. The nucleus consists of protons and neutrons. Particle physics has divided these particles into yet smaller entities. The theoretical physicist John Wheeler (who introduced the black hole as a concept) claimed that the "bit" was the smallest unit of information in the universe, and that the universe is a case of "it from bit" (Wheeler 1989). From here, nature can be built. With this thesis, Wheeler reversed the traditional approach of physics from "large to small" into "small to large." Today, we refer to qubits as being the smallest thinkable unit (Van Hal 2016). In ET terms, it can now be said that all existing levels of organization in the universe are constructed from qubits. Atoms, molecules, cells, humans, and societies are all levels of organization in which qubits have organized themselves.

The synthesis of proteins illustrates how the relationship between the different levels of organization works. The function of the protein is formed by the specific order of amino acids. Based on this order, it can fulfill a function in the cell. There are various levels of organization, which are connected in an interdependent interaction: the lower level with the diversity of amino acids; the in-between level of the protein itself with its three-dimensional form; and the higher level, which constitutes the function of the protein for the cell (e.g., as an enzyme). Both the emergence and the evolution of the interaction of the organizational levels have a dialectical nature: while in operation, each level plays a part in creating and sustaining the other levels to which it is connected. They evolve to higher levels of complexity and sustain themselves in symbiotic, dialectical relationships. This dynamic dialectical order is under constant pressure from the leveling action of the second law to relinquish its complexity and the information stored within it. Thanks to its dialectical coherence, both the system as a whole and its constituent parts have the potential to resist this leveling effect of the entropy maximization. The continuous dynamic interdependency is required for the organizational levels to remain stable, to survive, and to evolve.

The emergence and evolution of phenomena in nature are not "determined" in chains of linear causal relationships between singular parts. Dialectical relationships between various levels of organization do evolve in order to form larger wholes as well as to sustain constituting parts. Amino acids, proteins, and cells all work together. Bacteria and other micro-organisms in the body cooperate with human organisms. Plants and animals work together. Humans work together to form powerful communities, and communities in turn enable humans to become powerful individuals. Dialectical symbiosis is constitutive of evolution, as Lynn Margulis (1999) succinctly puts it. In contrast, ideas such as "survival of the fittest" and "struggle for life" one-sidedly 
place the emphasis in evolution on the productive interaction between singular parts. The evolution of larger wholes, dynamically formed by their constituent parts and vice versa, does not fit into this ontology. Bringing these "atomist" principles to the forefront removes the symbiotic power between parts and their higher levels of organization from the evolutionary dynamic.

Specific value is found in considering "effectivity," "redundancy," and "efficiency" from the ET perspective. For the evolution and stabilization of order, effectivity is an essential characteristic. The same holds true for the phenomenon of redundancy. The Last Eukaryotic Common Ancestor (LECA) evolved as an extremely complex biological structure. Soon much of this complexity was lost in evolution. From an efficiency perspective, this does not seem to be very efficient. Efficiency seems to be a most attractive property, since less energy is lost as entropy in energetic transitions. The high degree of complexity is a form of redundancy, but from an evolutionary perspective it is effective indeed: new levels of organization need to be built from it and the chance of failure is minimized through this stepping stone. It may be that less complicated eukaryotes, prior to LECA, would not have made it under the leveling pressure of the second law. Ultimately, from the LECA's complexity, evolutionary "knowledge" could evolve to also achieve efficiency.

Redundancy is property of evolutionary effectivity. In living nature, abundant quantities of seeds and sperm are produced for reproductive processes. Every evolutionary step stems from an abundant number of possibilities from which selections are made. In this way, the leveling force of entropy can best be resisted. Moreover, redundancy constitutes the potential for selecting the direction in which nature evolves. It is the eminent way to establish progress from evolved organizational levels to successive generations. To achieve evolutionary progress, natural phenomena are built on effectivity, redundancy, and efficiency. Often, these properties of resisting chaos compete for precedence. They need to be deployed in a careful balance to constitute evolutionary power.

In our anthropocentric, efficiency-driven world, this balance often seems to be disturbed. The extreme predominance of economistic orientations in our modern societies tends to be unilaterally based on efficiency thinking. Although many scholars - aware of the risks of a dangerous pandemic — did argue for redundancy in the capacity of hospitals, the COVID-19 crisis has meant that nearly every country has been confronted with a dramatic shortage of intensive-care beds (Marijnissen 2020). Long-lasting economistic efficiency thinking had reduced available capacity to just the numbers of beds needed in the business operations of the hospitals. The organization of redundancy was completely neglected. In many cases, the effectivity of patient care became seriously threatened. Unilateral emphasis on efficiency implied organizing risk so as to lose the ability to resist chaos-in thermodynamic terms, entropy maximization.

With the evolution of higher levels of organization, new laws have and may still come into being. Verlinde (2011) has mentioned this in the context of the appear- 
ance of gravity in the universe. New laws have also been determined for the working of the carbon atom, as have laws governing living nature. The rise of new laws is not in conflict with Spinozan ontology, stating that Nature is a unity. The laws governing evolution are consistent with the universal unity of Nature. As levels of organization, they build on one another to create functional wholes that are able to resist the leveling effect of entropy maximization. Considering the onset of evolutionary processes from the Big Bang in the universe, the workings of the laws of ET have always been present.

For Spinoza, the (Cartesian) concept of conatus, which he adopted, became the central concept for understanding the workings of Nature. He viewed conatus as the driving force for its evolution. Long-accepted reasoning in physics has resulted in considerable trepidation about describing phenomena in nature that can possibly be viewed as anthropocentric. In physics, the anthropocentric concept of "force" tends to be sterilized. So it no longer refers to Achilles defeating Hector with his awesome "force": Verlinde, for example, considers gravity as an "entropic force." In biology too, scientists tend to have allergic reactions to potentially anthropocentric views. Using the concept of conatus therefore may be seen as highly suspicious. In the perspective of the ET argument, it is attractive to consider the evolutionary "force" that results from the tension evoked by entropy maximization as conatus. Conatus then becomes the force that brings about the ordering effect of the second law of thermodynamics. It clarifies a great deal about evolutionary phenomena, from Verlinde's gravity to the biological evolution of plants, animals, and humans and their societies.

\section{Part 2: Links between Human and other Sciences: SQA as a Case}

In Part 1, the concept of evolutionary thermodynamics (ET) was developed in order to explain evolutionary processes in the natural world in full compliance with the fundamental laws of physics. It therefore offers an interesting tool to open crossdiscipline dialogue between physics, biology, and other natural sciences. Inspired by the ET concept, Part 2 focuses on exploring scientific tools to interconnect knowledge inherent to the human sciences and other sciences. The content of Part 2 is a quest for an appropriate human scientific approach that could fulfill a connecting role similar to that of ET. This implies that the ontological pattern of such an approach needs to have a basic affinity with the ontological features described under ET for the essence of evolutionary processes. The proposition of ET is, first, that nature-in the Spinozan sense-is a unity constituted of interconnected phenomena and laws. These evolve in dynamic dialectical processes between levels of complexity. It will be hypothesized that, as a particular expression of the human sciences, the social quality approach (SQA) implicitly endorses the same basic assumptions as ET.

To articulate the particular nature of the SQA, its ontological and epistemological characteristics will be explicated through some historical references to aspects of the development of the human sciences. We reveal that the origins of the SQA 
derive from criticism of "positivistic (empiricist) individualism" and "positivistic (empiricist) organicism." Both discourses refer to the points of departure of the Newtonian and Scottish philosophers. These origins are helpful in explaining the implicit affinity with the basic assumptions of ET. As was the case with the scientific discourses of Descartes, Spinoza, Newton, and Darwin in the case of the natural sciences, an analysis of relevant human scientific discourses in the eighteenth, nineteenth, and twentieth centuries in the Western Hemisphere helps to enlighten the argument. We argue that the SQA has the potential to be functional in connecting diverse, fragmented, scientific natural and human discourses. Considering today's enormous global challenges-above all the need to create overall sustainability of human existence on earth-we conclude that it is a moral obligation for scientists in physics and other natural sciences and the human sciences to open up dialogue and seek cooperation.

\section{Development of Human Sciences in the Western Hemisphere}

Inspired by manifold European philosophers, scientists, literati, and artists at the end of the eighteenth century, economics and political science emerged as the first of the human sciences in the Western Hemisphere. They had their roots in the Enlightenment, with its claims for a new "science of mechanics." At least three societal changes explain the emergence of these new sciences. First, the perpetuation of power relationships became a prominent issue in societies. The nation itself was a new concept at that time, and the Russian, Prussian, Swedish, Habsburg, and French regimes were for the first time defined as powers of nations. The idea of the nation was the context in which the development of the new sciences could take place. Second, the transformation of feudalism into capitalism, especially in the Western Hemisphere, became an important context. Third, the Industrial Revolution, starting with Britain, was a strong stimulating force, through which the emergence of the new sciences could take place. This last transformation in particular emphasized the need for the development of a science of mechanics. For capitalist technological development, physics and other natural sciences became vital resources.

Reliance on investigation of the objective (empiricism), which had its roots in Newtonian thought, was central to the scientific and technological approaches (Gollobin 1986). Here, the emerging economic and political sciences were strongly influenced by the instrumental character of the science of mechanics. These first human sciences were intended to create instruments to develop better understanding of societal processes taking place in the various nations. This understanding was expected to serve in steering societal processes in the right direction. At the time, the right direction was of course determined by the elites who were in power (Martindale 1960). The idea of the nation also constituted the historical momentum where the roots lay of the philosophies of the founding fathers of the Enlightenment, both the Scottish moral philosophers and the French interpreters. 
Empiricist, mechanistic discourse was the intellectual source for the Scottish moral philosophers. It paved the way for an atomist-oriented scientific analysis of societies. The underlying ontological thesis was that societies are aggregates of individual human beings who, from an egocentric perspective, are striving for positive individual outcomes and preventing negative ones (Vanberg 1975). According to Roy Bhaskar (1978), in the philosophical sense, this thesis is legitimized with the general acceptance of the "epistemic fallacy" as presented by David Hume, who was also inspired by the work of Newton. The latter explained that real knowledge was limited to only the outward, sensorily graspable level of things (Gollobin 1986). Arguing from there, Bhaskar stated that,

first, knowledge is reduced to that of atomistic events apprehended in sense-experience. Secondly, these events are then identified as the particulars of the world. . . . From Hume onwards, philosophers have thus allowed, for the sake of avoiding ontology, a particular concept of our knowledge of reality, which they may wish to explicitly reject, to inform and implicitly define their concept of the reality known by science. (Bhaskar 1978: 41)

In the epistemological sense, this implies that what we can know in order to exist is just a part of what we would possibly be able to know.

For the French interpreters in the early nineteenth century, their intellectual sources were twofold. The work of Saint Simon and August Comte played an important role. The French scholars in particular addressed the comprehension of the evolutionary laws expressed in the history of societies. By understanding these laws, knowledge would be available for the deployment of political and economic steering instruments. With this knowledge, one could forecast (and of course control) the development of the future of societies. According to Comte, this meant that a new science had to be established, which he referred to as "sociology" (Vanberg 1975). Don Martindale states that Comte became remarkably popular because he combined the principles of physics, resulting in "positivistic (empiricist) individualism" and conservatism oriented to "positivistic (empiricist) organicism" (1960: 63). Conservatism at that time was an attractive sociopolitical perspective with which to preserve a particular desired characteristic of society. However, the combination of the two completely different epistemological orientations-accepting the "epistemic fallacy" -implied a serious epistemological contradiction. This friction was masked by the lack of serious explicit ontological considerations. The topical enthusiasm for organicism was strongly stimulated by the prestige of biological science at the time. This connection with biology reinforced the emphasis on "positivistic empiricism" (Martindale 1960: 122).

Emile Durkheim and Ferdinand Tönnies would later eliminate Comte's epistemological contradictions by postulating societal phenomena as "things" ("facts") with sui generis powers. These "facts" are considered exterior to and have a decisive impact on humans as members of society. According to Viktor Vanberg, this interpretation presents an example of "an a priori thesis of the ontological reality leap" (1975: 159). The 
ontological aspects are simply not discussed. The reality is that, due to the association and interacting of individual people, societal configurations and related phenomena come into being. Because of this leap, these configurations cannot be understood by explaining the nature and the actions of these individual people. This societal context forms an integrated entity that is in a sense comparable to that of a living organism (Giddens 1971). Because of his "social facts" as specific phenomena, Comte's positivism is not identical with radical empiricism or with the positivism of the Vienna Circle. As Martindale observed: "In fusing organicism to [his form of] positivism, sociology proposed to convert the empiricist-positivistic tradition of the West to conservative ends" (1960: 122). As a consequence, in this vision people and society are not dialectically related: "They do not constitute two moments of the same process. Rather they refer to radically different kinds of things" (Bhaskar 1979: 42). This assumption is in accordance with the individualistic discourse of the Scottish philosophers, which is in turn connected with Newtonian physics.

In the middle of the nineteenth century, a fundamental critique appeared on the scene regarding the two predominant epistemological orientations, the "positivisticindividualism" and the "positivistic-organicism." From the human sciences, Karl Marx and Friedrich Engels came to the fore as powerful critics. In their ontology, "relationality" became a fundamental concept. They postulated that "relationality" is not simply a product of human interaction. It should be considered as a matter of "constitution of practice." As Bertell Ollman summarizes their interpretation:

Capital, labor, value, commodity, etc., are relations, containing in themselves, as integral elements of what they are, those parts with which we tend to see them externally tied. . . This view does not rule out the existence of a core notion for each factor, but treats this core notion itself as a cluster of relations. (Ollman 1976: 14-15)

\section{Frictions in Merging Physics and the Human Sciences}

Proponents of both "positivistic-individualism" and "positivistic-organicism" did not care about the implicit ontological choices underlying their epistemological approaches. At the time, biology and the human sciences were considered to be secondary to physics. From their (explicit) epistemologies and their (implicit) ontologies, they blindly attempted to adhere to Newtonian principles and the discourse of the Scottish philosophers. The irreversibility of time, of course, had to be accepted as an ontological principle in the discourse of the human sciences: humans and societies clearly do change over time. Yet, in the endeavor to come as close as possible to Newtonian principles, epistemological approaches were built on the idea of time reversibility. Time should have as little influence as possible in research. In the human sciences, research and experiments on observable individual subjects needed to be reproducible. As in physics, uncovering the truth about humans and their societies was best approached by way of causal models and reproducible experiments. 
The influence of the physical sciences on the human sciences has ever since continued to play a decisive role in many scientific discourses. In this light, the thesis of Michael Friedman speaks volumes. Friedman's interpretation plays-rightly or wrongly — a role in the development of the SQA, where a sharp distinction is made between the radical "empiricism" and the "positivism" of the Vienna Circle (Herrmann et al. 2012). The Vienna Circle was an open platform for philosophers, artists, and scientists to discuss the physical, biological, and political sciences, economics, and sociology. From the groundbreaking insights of the Vienna Circle, Friedman studied the changes in the physical sciences in the late nineteenth and early twentieth centuries. Friedman hypothesized that the philosophy of sciences underlying the human sciences was highly indebted to physics and the natural sciences. Immanuel Kant's assumptions were intrinsically connected with Newtonian thought. Friedman concluded that thanks to the progress in natural sciences, the Kantian a priori was no longer tenable: "Developments in mathematics and physics upset this Kantian synthesis from all sides. Nineteenth-century foundational work-especially Karl Weierstrass's 'rigorization' of analysis and David Hilbert's Foundations of Geometry-upset Kant's concept of mathematical reasoning. . . . Later, Albert Einstein's work on relativity upsets Kant's conception of physical reasoning" (1999: 21). In his argument, Friedman refers to Moritz Schlick, who argued that "general relativity [see Einstein] is quite incompatible with pure intuition [see Kant], of course, because space can no longer be conceived as a separate and independent property, ... entirely independent of the physical conditions prevailing in space" (1999: 40). Friedman implicitly seems to repeat a very traditional assumption about the primacy of the physical sciences. Friedman's thesis therefore needs to be questioned, and it becomes relevant for the discussion of the assumptions made regarding the SQA and ET.

Today, manifold epistemological approaches can be observed in the human sciences. The approaches applied are often more or less articulate in their epistemological methodologies (e.g., objectivist, quantitative, hermeneutic, constructivist, qualitative, or discourse analysis). As was the case in the early stages of the human sciences, the applied methodologies are rarely explicitly connected to particular ontologies of humans and their societies. Clearly, many approaches in the human sciences today implicitly still basically rest on Newtonian principles adopted at the onset of the human sciences. In econometrics, for example — from an epistemological atomist perspective—societies are basically considered as "collections of individuals." Statistics are compiled on aggregates of observations on characteristics of individual subjects to determine whether causal relationships can be uncovered. Little to no account is taken of the complex interactions with other layers of societal organization (complexities) in which they take part. From this epistemology, individuals are completely disconnected from a multitude of reciprocal processes between societies and their members that influence the nature of daily economic conditions.

The question is whether the truth about the complex reality of humans and societies can be uncovered through the deployment of the epistemological approach, in 
which the only real subjects of science-in accordance with the Scottish philosophical discourse-are "sense experiences." At the start of the development of the SQA, it was questioned which ontological and epistemological framework had true validity and heuristic meaning for understanding the reality of processes taking place among humans and in their societies. In the quest for an answer to this fundamental question, an endeavor was made to articulate four basic ontological-epistemological ground patterns of thought that can be derived from the history of the human sciences. The grouping into these patterns may pave the way for identifying human scientific ontologies that have particular affinity with the essence of the ET concept.

\section{Four Ontological Ground Patterns as Points of Reference}

Four prominent ontological-epistemological ground patterns of thought proved to have been very influential for the development of distinct Western human sciences in the nineteenth and twentieth centuries. The study of the supposed similarities and differences of the four ground patterns of thought was part of the pioneering work that underlines the SQA. The grouping of these patterns is based on seven studies (Berting 1985; Bhaskar 1978; Bhaskar 1979; Giddens 1971; Ossowski 1962; Vanberg 1975; Van der Maesen 1987). In the analysis, it is assumed that in each of the four patterns a particular ontology induces an affinity with a particular epistemology. The abovementioned scholars have many similarities in identifying the distinctions presented below. In Max Weber's terms, the pattern groupings represent "ideal types" (Martindale 1960: 382). Adherents of one pattern may also have some kind of affinity with aspects of other patterns. An astute insight into this "ideally typical distinction" is a precondition for the understanding of the contemporary relationship or nonrelationship with physical and biological sciences. For the SQA, it had a heuristic meaning for determining its own theoretical position in contemporary human scientific discourse (Herrmann et al. 2012). Below, we distinguish the four patterns, and we pay particular attention to their ontological roots, their epistemological consequences, and, above all, their logically based interrelationship.

1. Mechanical utilitarianism became the ontological ground pattern of the epistemological approach of "positivistic methodological individualism." The economist Vilfredo Pareto (1848-1923) was a distinguished adherent of this framework. Its ontology rejects the existence of dynamic societal complexities. In its epistemology, societal configurations are reduced to the singular parts that together constitute complex configurations. This individualistic reduction denies the reciprocal interaction between humans and social configurations. Among other things, it underlies the disconnection of economic processes from complex political, juridical, and sociocultural processes, which are revealed in, for instance, dissocialized labor power (Lebowitz 1973).

2. Constructive voluntarism became the ontological ground pattern for the epistemological approach of "hermeneutic methodological individualism." Max Weber 
(1864-1920) was a distinguished adherent of this pattern. As an economist and sociologist, he considered the constitution of the social as a matter of rational decisions by individuals. According to Bhaskar (1979), the essential problem with this position is that to explain a human action by reference to its rationality is to explain some natural event by reference to its being caused as such. Weber emphasized the essential difference between the objective nature of physical sciences and the symbolic nature of "social sciences." According to Hans Gerth and C. Wright Mills (1958), for Weber an "elective affinity" can only exist between the reality of material facts and symbolic actions.

3. Dialectical materialism became the ontological point of departure for the epistemological perspective of "relational collectivism." Karl Marx (1818-1883) and Friedrich Engels (1820-1895) are its most prominent spiritual fathers. According to Ollman (1976), this epistemological position is focused on the connection with systems, biographical development, and communities. In many cases, the affinity of this pattern with the natural sciences, biology in particular, has been overstressed. The preference of research on determinants and inevitable laws in the history of societies is often overemphasized. The ontological essence in this pattern of the "dialectic between processes of self-realization of human beings and the formation of collective identities" (Ollman 1976: 232) is often gravely underestimated. This neglect is due to, among other things, the breakdown of knowledge between competing scientific disciplines, each controlling its own subject matter, goals, and methods.

4. Structural functionalism, its most important adherent being Emile Durkheim (1858-1917), became the ontological point of departure for "positivistic (organic) collectivism" as an epistemological approach. The key concepts of Durkheim's ontology are "conscience," "collective," and "anomie." Bhaskar (1979) states that these concepts derive their meaning from their relationship to the collective nature of societal phenomena. As noted above, according to Durkheim social facts are the outcomes of the connections of individuals. They constitute facts sui generis and are the ultimate objectification or externalization of human beings. Vanberg notes that this interpretation consequently presents an example of a "priority thesis of the ontological reality leap" from individuals to societal facts sui generis (1975: 159). For Durkheim, "social facts" are reifications and not conceived in a dialectical way as a methodological or heuristic instrument for analyzing contradictions in essential structures, rather than, or at least in addition to, empirical regularities (Bhaskar 1978: 38-41; Bhaskar, 1993: 375).

\section{Nature as a Unity and Dialectic Ontology}

The appreciation of Nature as a Spinozan unity in which ontologies regarding natural and human phenomena coherently come together has been discussed in the work of influential scholars, stemming from diverse scientific discourses.

According to Ira Gollobin (1986), the above-mentioned distinction of patterns concerns the "philosophy of science" and not "scientific philosophy." The latter refers 
to philosophy that is scientific and excludes nonscientific formulations. The first is comprehensively oriented and covers the general scientific aspects of all spheres, including the arts and special sciences. Marx and Engels presented an expressive nineteenth-century example of this comprehensive vision. Gollobin argues that thanks to their comprehensive approach they were able to conclude that scientific philosophy and human sciences were born "as revolutionary twins, defying the capitalist status quo with traditional property relations, which should inevitably have to change, and which changes involve the most radical rupture with traditional ideas" (Gollobin 1986: 43).

Another less well-known but influential twentieth-century scholar was Lawrence Henderson. He was one of those who introduced Pareto's positivistic "methodological individualism" in the United States. He was a distinguished physiologist, biochemist, and sociologist, and is valued as the tutor of leading sociologists in the United States, including Talcott Parsons and Robert Merton (Henderson 1967). In 1913, he concluded that "the properties of matter and the course of cosmic evolution intimately related to the structure of the living being and to its activities [and] the whole evolutionary process, both cosmic and organic, is one, and the biologist may now rightly regard the universe in its very essence as biocentric" (Dick 2001: 261).

In the same vein, Ervin Laszlo (1987) later extended the perspective of physics and biological sciences to human sciences. He argues—regarding the connection of patterns of transformation in the cosmos, biological species, and modern societythat a new grand evolutionary synthesis is possible. According to Laszlo, this grand synthesis makes where human beings are in nature's scheme understandable. It also enables us to identify particular processes that determine the future of our societies. Prigogine underlined the fact that Laszlo's work delivers a comprehensive overview, which increases our understanding of the universe and the place of human beings within it (Laszlo 1987). Laszlo states that "evolving systems are not closed; the universe as a whole is not mechanistic; cosmic processes do not point the arrow of time toward a state of universal heat-death; and life is neither an accidental aberration nor the manifestation of mysterious metaphysical forces" (1987: 17). Laszlo's argument more specifically places the evolution of humans and societies as an integral part of the evolution of the cosmos. His argument shares many similarities with the ET concept. According to Spinozan thought, Nature is a unity in which all phenomena, of living and nonliving nature, as well as humans and societies are interconnected.

Laszlo also argues that time-irreversible evolution takes place. However, he has not thoroughly elaborated the specific ontological nature of the evolutionary processes. Laszlo postulates that evolutionary processes take place in open systems. ET takes a further step by demonstrating that evolution is possible in isolated systems, and therefore is a characteristic of the second law of thermodynamics. It consequently brings evolutionary processes under the regime of the fundamental laws of physics. It further explains that in open systems evolutionary processes are reinforced and can be sped up. The assumption of ET is that evolutionary processes basically have a dialectical 
character, whereby the coherent dynamic between different evolved levels of organization does have the potential to resist the leveling power of entropy maximization. Its ontological point of departure is that evolution in nature is based on the coherent dialectic between different levels of evolving complexity.

The Austrian philosopher Wolfgang Röd (1986) analyzed the nature and origins of different interpretations of dialectics since ancient times, in order to understand contemporary dialectical philosophy. He concluded that we have to pay a high price for this, because of the utmost level of complexity of the related notions. Bhaskar took up the gauntlet and developed a contemporary critical theory of humans and societies based on dialectical thinking. Bhaskar's philosophy of science is referred to as "critical realism." In an ontological sense, this means that societal totality must be regarded as "an ensemble of structures, practices and conventions which individuals reproduce or transform, but which would not exist unless they did so. Society does not exist independently of human activity (the error or reification). But it also is not the product of it (the error of voluntarism)" (1979: 45-46). Epistemologically, this means that methodological approaches are needed that go beyond the various ontological interpretations of "dialectic," as conceived in Heraclitian, Socratic, Aristotelian, Schillerian, Kantian, Hegelian, Marxian, or Sartrian ideas, among others. These ideas do not address the essence of "critical realism" (Bhaskar 1994). As Andrew Collier summarizes Bhaskar's interpretation of this dialectic:

Bhaskar's emergence theory allows us to conceive of real, irreducible wholes, which are composed of parts that are themselves real irreducible wholes. At the same time, they in turn are parts of larger wholes. With each level of this hierarchy of composition having its own peculiar mechanism and emergent powers, this in turn allows us to understand dysfunctions in these wholes that are functional in character, since the parts are not pure functions of the whole, but go their own way as well. The one word for such a theory of potentially dysfunctional wholes is "dialectic." (Collier 1994: 117)

Bhaskar's argument lies in his critique of today's philosophy:

Today, philosophy, for the most part, only reflects the superficial sheen of reality (there is no depth), normalizes the status quo ante (there was history, but, like ideology, it is no more), sequesters existential questions and legitimates the spread of more of the shallow same, treats relations as external and contingent (disconnecting, as it screens, contradictions and conflict), and perpetuates the combination of a physicalistic reductionism and dualistic disembodiment (reification and voluntarism). (Bhaskar 1994: x)

So we have to do this job because "scientific discovery and development entails that scientific inferences must be analogical and retroductive, not simply inductive and/ or deductive ('logic'); and that the process of knowledge production necessitates a conceptual system based on the notion of powers ('metaphysics')" (Bhaskar 1979: 
24). In an epistemological sense, Bhaskar argues that the production of knowledge regarding the search for truth requires a carefully composed combination of methodologies, in which power relationships between stakeholders are to be taken into account. Baskhar's essential thesis on dialectics became the point of departure for the development of the SQA, which was elaborated in Social Quality: From Theory to Indicators (Van der Maesen and Walker 2012). The challenge is that substantiating "critical realism" does imply a new critically realistic "dialectic."

\section{The SQA: Comprehensive Conceptual Framework}

The social quality approach (SQA) was developed in the late 1990s (Beck et al. 1997). It has since been further developed and applied. ${ }^{1}$ The beginnings of the SQA stem from meetings of European experts, which were held in Amsterdam. The fundamental reason for its development was to critically address the dominant neoliberal economistic approach of member states of the European Union. A critique was developed regarding the European Union's economic politics and policies, which were explained to be based on the principles of "mechanical utilitarianism." Essential aspects of the daily circumstances of people's lives in policies were conceived to be mere handmaidens of this politics. The European Union's official target during the first part of the twenty-first century was exemplary: "To precipitate social protection as a productive factor" (Beck et al. 2001: 336). It should, of course, also be productive for economic politics.

The ontological and epistemological points of departure of the SQA correspond with this founding critique. The greater mission of the carriers of the theory became and still is a thorough understanding of "the social." The concept of the social was conceived as (1) a comprehensive concept about main structures and mechanisms, which is applicable in all relevant disciplines; (2) an alignment of a comparable orientation in various disciplines of herewith related general patterns of events; and (3) a means to pave the way for tuning interpretations of relevant experiences with their empirical expressions (Beck et al. 2001). This essential perspective on "the social" is consistent with Bhaskar's critique on "empirical realism," which indeed fails to understand the meaning of this distinction between the "concrete," "abstract," and "empirical" (Bhaskar 1978, 1979).

"The social," according to the theory, is conceived in three categories. First, there are the outcomes of the dialectic between processes of self-realization of humans as social beings and processes constituting collective formations and identities. This refers to structures and mechanisms, or the realm of the "concrete" (Beck et al. 2012). Then, there are the processes at stake that are realized through the interaction of two basic tensions: (1) the horizontal tension between the world of families, communities, and networks and the world of systems, institutions, and organizations; (2) the vertical tension between societal transformations and biographical transformations (Beck et al. 2012). These patterns belong to the realm of the "abstract." Third, there are the 
outcomes of this realization, which result in productive and reproductive interrelations of human beings at a specific time and place. These result in three empirical categories: (1) the set of constitutional/subjective factors; (2) the set of conditional/objective factors; and (3) the set of normative/ethical factors (Beck et al 2012). This refers to the realm of the "empirical."

The specific ontology of "the social' in the SQA can be articulated by assigning it a position in the spectrum of the four ground patterns outlined above (Herrmann et al. 2012). Social quality has no real affinity with the patterns of mechanical utilitarianism and structural functionalism. The one-sided primacy of the individual in the first pattern and the primacy of the collective in the fourth strongly contradict the assumption of social quality that "dialectic processes do result in the self-realization of individuals and the formation of collectivities and collective identities" (Beck et al. 2012: 48). From this perspective, the SQA indeed has more affinity with the second pattern of constructive voluntarism. It cannot be fully equated with this pattern, however, since the dialectic formation of collectivities is not part of its ontology. Lastly, the SQA definitely has a strong affinity with the third pattern of dialectic materialism. Nonetheless, it also basically distinguishes itself from this ontology, which largely neglects the outcomes of the dialectical processes in terms of the self-realization of humans. The essence is that the basic ontology of the SQA assigns equal significance to the "selfrealization of individuals" and the "formation of collectivities and collective identities." It consequently avoids the systemic one-sidedness of the other patterns and takes a distinct, unique position in the spectrum of ground patterns.

Social quality is identified as the dynamic outcome concept of the SQA. It is defined as "the extent to which people are able to participate in social or societal dimensions of life (sociopolitical, socioeconomic, sociocultural, and socioenvironmental) and the development of their communities under conditions that enhance their well-being and individual potentials, which enables them, in turn, to influence the conditions of their own existence" (IASQ 2019). Its ontological assumptions stem from interpretations of the social, which is to say the interpretation of humans as social beings. From there, the three above-mentioned sets of factors influencing social quality are identified. The interpretation of the outcomes of the dialectic between constitutional and conditional factors by means of the application of the normative factors delivers a better understanding of the direction in which social quality develops.

It is common in human scientific research not to refer explicitly to underlying epistemological principles, let alone the ontological assumptions on which these principles are based. The defined ontology of the SQA is logically connected to its epistemological points of departure. These constitute the research instruments stemming from epistemological considerations regarding the interpretation of structures and mechanisms of the "dialectic between processes of self-realization and the formation of collective identities constituting the social" (Beck et al. 2012: 48). From the analytical framework of the SQA, diverse research methodologies, ranging from objectivist to constructivist in character, are applied. The SQA encompasses a range of research 
methodologies in order to comprehend objective, subjective, and normative aspects of the dialectics leading to social quality. Sociopolitical/juridical, socioeconomic/financial, and sociocultural/welfare (dialectical) processes are seen as subjects of attention for the SQA. From its comprehensive focus on the social, sustainability is conceived as an overall quality of the above-mentioned interconnected societal dimensions. Sustainability has become one of the major focuses of attention of the SQA.

With this comprehensive ontology, the SQA expresses close affinity with the ET concept. In ET, the dialectical coherence of evolved levels of organization constitutes the force to be able to resist the leveling pressure to lose order (information). Based on this ability, evolution becomes possible. The conatus, then, is the decisive force, driving the evolution forward. In the ontology of the SQA, the dialectic between humans and societal configurations constitutes the dynamic force of progress in the evolution of humankind. It shelters in the dialectics leading to a specific extent of social quality. The direction in which the evolution of social quality is driven is-as assumed in ET for nature as a whole - to a large extent unpredictable. According to assumptions of the SQA "social justice," "equal value," "solidarity," "human dignity," and "eco-equilibrium" are essential normative factors that give shape and direction to the evolution of social quality (IASQ 2019: 10). These "good" normative factors, successful in operation, can be seen as the immanent contribution of humankind to the conatus as a force that drives the evolution on our earth in the "right" direction.

\section{Conclusion: Two Catalysts for Border-Crossing Dialogues}

In this argument, some far-reaching theoretical assumptions have been made concerning some obstacles that obstruct a thorough, coherent comprehension of nature. These assumptions are intended to stimulate debate. The argument presented in Part 1 makes it clear that ET is essential for achieving a coherent understanding of nature, that is, both living and nonliving reality. As a theoretical link, ET has an interesting potential for building cohesion between physics, biology, and the human sciences. It also carries serious ramifications for theoretical physics, for which thermodynamics may be fundamental, but in a particular sense secondary. The time-reversible laws of Newton and others are still often seen as primary. The persistence of the primacy of time reversibility can perhaps be best observed in the argument of Nobel Prize winner Richard Feynman (Feynman 1987). He argued that time irreversibility does exist, albeit only in its appearance at the macro level. He thereby denied it as an ontological essence, but judged it as a statistical phenomenon. At the micro level, time remains reversible.

In ET, however, it is assumed that-in the ontological sense-time-irreversible formation of higher levels of organization both in isolated and open systems is indeed possible. In this formation of symbiotic levels of organizational complexity, resistance is built against the leveling force of entropy maximization. The evolutionary processes 
do evolve in interdependent, coherent dialectical relationships between these different levels of complexity.

ET provides a foundation for the evolution of nature according to the laws of physics. Theoretically, however, physics persistently seems to deny the ontological essence of evolution. Where the possibility of evolution is concerned, physics needs to put its own discourse in order. To this end, many incentives have already been provided in order to establish links between physics and the other natural sciences. The fragmentation between physics, other natural sciences and the human sciences continues to disturb and disrupt the development of comprehensive, coherent knowledge about the workings of processes in nature. To achieve such coherent comprehension, the Spinozan starting point that Nature is a unity and needs a single explanatory approach should be valued as the fundamental ground motif for all the sciences. As a connecting concept, ET is shown to have the potential to bridge the theoretical divide between physics and the other natural sciences.

Inspired by the ET hypothesis, Part 2 unfolds explorations to identify human scientific theoretical frameworks that imply similar connecting potentialities. Such frameworks may constitute tools that can connect the human sciences, biology, other natural sciences, and physics. Here, a common ground can be found for dialogue between the diversity of sciences. In search for appropriate ontologies and epistemologies, an exploration of the most influential ground patterns of thought, applied in the human sciences, was unfolded. It was concluded that both "individualistic" and "collectivistic" perspectives were one-sidedly oriented, respectively, to humans as autonomous interacting singular parts and societies as larger collectives sui generis. The nature of processes of evolution of humans and societies is assumed to be most adequately expressed in a new understanding of the social. It was hypothesized that the SQA expresses much affinity with the principles of ET theory. For both, dialectical evolutionary dynamics between constituting parts and larger wholes constitute the common ontological ground. Based on this dialectical pattern, living, nonliving, and human phenomena can be conceived and studied as interrelated phenomena of Spinozan unified Nature.

The SQA has been built with a strong, comprehensive epistemological orientation. From its comprehensive ontology, the human experience (the subjective), the reality of societal conditions (the objective), and the ethical aspects (the normative) are part of its analytical framework. Since the social is its core concept of thought, the theory is applicable in any societal dimension: sociopolitical/legal, socioeconomic/financial, sociocultural/welfare, and socioecological. This last dimension has become crucial. Overall sustainability has increasingly become an overarching point of departure in societal and ecological systems. From this perspective, the SQA —as is the case with ET-encompasses an interesting potential to function as a catalyzing tool to cross scientific borders and unite different scientific disciplines in a collaborative endeavor.

Considering the extremely complex nature of many pressing global problems, coherent scientific knowledge is urgently needed. It is a conditio sine qua non to cope 
with today's critical challenges in the world. Defending and developing the overall sustainability of nature and human existence is undoubtedly one of the most prominent issues of our time (IASQ 2012, 2019).

Another complex issue, which stands as an inexorable sign on the wall is that 26 percent of today's urban world population lives in slums, and that number will increase significantly in the future (UN-Habitat 2016). The ongoing COVID-19 pandemic is yet another example of a pressing, topical global issue. This crisis painfully reveals the complex physical, biological, societal, and human interferences that cause far-reaching economic, cultural, and ecological imbalances. It is an evident threat to global overall sustainability. Resuming business as usual would mean serious headin-the-sand behavior concerning the enormous consequences of the imbalance of the interferences at stake.

The sciences have developed in rather fragmented, super-specialized subcultures of expertise. The specialized products of these cultures are not accessible for common human consciousness. It has become increasingly difficult to synthesize knowledge from these subcultures into a comprehensive understanding of complex problems (Habermas 1981). Finding solutions for the complex pluralist nature of global issues requires coherent and integrated knowledge and the input from multiple scientific disciplines. The required collaboration is currently inhibited by a whole range of conditions, such as paradigmatic isolation, economic interests, and rusted traditional behaviors.

Theoretically, such catalysts as ET and the SQA can contribute to stimulating interdisciplinary dialogue. Picking up the baton and actually doing this is primarily the moral responsibility of the fragmented scientific communities. Laszlo is explicit about the responsibilities of the representatives of the sciences in today's digital world. He argues that people living in contemporary, highly specialized societies need understandable, detailed, and reliable information on socioeconomic, sociopolitical, sociocultural, and socioecological ties. He further argues that the evolutionary task of scientists is to place the acquisition of relevant knowledge at the very top of their research priorities.

Today, this challenge is seriously complicated by the greater evolution of technologies. Nevertheless, Laszlo makes a strong plea to scientists that

technologies that automate the everyday activities of people and discourage face-to-face contact lead ultimately to depersonalization and alienation. Technologies that enable distant power centers to spy on people, to control their movements and their self-expressions constrain individual freedom. . . But this need not be: new technologies could be created that encourage individual freedom and creativity and contact among free and creative individuals. . . Attention to the effect of new technological innovations, especially in the fields of information, communication, and automation, is a responsibility first of all of those who generate the innovations - the physical scientists and engineers actively engaged in research and development. (Laszlo 1987: 147) 
Laszlo's plea, although correct, is remarkably confined to technical experts. He seemingly denies the influence of sociopolitical and socioeconomic dimensions in his envisioned improvements. But his argument for more comprehensive approaches concerns all sciences and areas of expertise, including the human sciences.

As stated above, this argument is not just an interesting theoretical exercise. Crossing scientific borders is a strong moral obligation in the light of the three great realms of evolution: the physical realm of the evolution of matter, the biological realm of the evolution of life, and the realm of the evolution of humans and societies, and, even more importantly, the coherence among all of these. More than ever, we need new connecting scientific orientations to comprehend and therefore to cope with today's global challenges. The assumptions of the ET concept and the SQA have interesting potentialities. There is no time left for naïvely opportunistic approaches. As constituent beings of Spinozan Nature, the direction in which the conatus (as immanent force) drives the evolution of our earth to a considerable extent lies in our own hands as human beings. It is our moral duty to take good care of it by respecting normative criteria that we are invited to put forward and agree upon.

\section{Acknowledgments}

We greatly acknowledge the assistance of Mari Shields in translating and editing the text for this article.

Jaap Westbroek studied biology and biochemistry at the University of Leiden. He held various positions as lecturer, manager, and innovator of educational institutions, including as CEO of Esloo College in The Hague. Throughout his career, the quest for physical explanations of biological evolution has continued to fascinate him. Since 2017, he has systematically probed the relationship between (biological) evolution and thermodynamics. The major arguments of Part 1 concerning physics, biology, and evolutionary sciences are the fruits of this longstanding fascination.

Email: jaapwestbroek@me.com

Harry Nijhuis was trained at the University of Nijmegen and the Johns Hopkins School of Public Health in Baltimore. He worked as a medical doctor and public health expert (specialized in anthropological and societal health issues). His major executive and academic appointments were as Head of the Department of Public Health, Municipality of The Hague, and as Professor of Urban Public Health at the University of Amsterdam. His contribution principally concerns Part 2 and the interpretation and translation of the essentials of ET into the principles of human scientific thought and the SQA. Email: hgjnijhuis@gmail.com 
Laurent van der Maesen studied political and economic sciences at the University of Amsterdam. He was engaged for two decades in the urban development of Amsterdam (Southeast). He has held various academic positions as Senior Researcher, among others, at the Interuniversity Institute of Social Scientific Research, Amsterdam. He was one of the founders of the SQA, and is the director of the International Association on Social Quality. He is currently Editor-in-Chief of the International Journal of Social Quality. He contributed to Part 2 of this article.

Email: vandermaesen@planet.nl

\section{Note}

1. See https://www.socialquality.org/.

\section{References}

Beck, W. A., L. J. G. van der Maesen, and A. C. Walker, eds. 1997. The Social Quality of Europe. The Hague: Kluwer Law International.

Beck, W. A., F. Thomése, L. J. G. van der Maesen, and A. C. Walker, eds. 2001. Social Quality: A Vision for Europe. The Hague: Kluwer Law International.

Beck, W. A., L. J. G. van der Maesen, and A. C. Walker. 2012. “Theoretical Foundations.” In Social Quality: From Theory to Indicators, ed. L. J. G. van der Maesen and A .C. Walker, 44-69. London: Palgrave Macmillan.

Berting, J. 1985. Grondpatronen in het denken over sociale ongelijkheid [Ground patterns in thinking about social inequality]. Assen, The Netherlands: Van Gorcum.

Bhaskar, R. 1978. A Realist Theory of Science. Sussex, UK: The Harvester Press.

Bhaskar, R. 1979. The Possibility of Naturalism: A Philosophical Critique of the Contemporary Human Sciences. Sussex, UK: The Harvester Press.

Bhaskar, R. 1993. Dialectic: The Pulse for Freedom. London: Verso.

Bhaskar, R. 1994. Plato Etc: The Problems of Philosophy and Their Resolution. London: Verso.

Clausius, R. 1865. "Über verschiedene für die Anwendung bequeme Formen der Hauptgleichungen der mechanischen Wärmetheorie" [About various convenient forms of the main equations of mechanical heat theory]. Annalen der Physik [Annals of physics] 201 (7): 353-400.

Cohen, F. 2007. De herschepping van de wereld: Het ontstaan van de moderne natuurwetenschappen verklaard [The recreation of the world: The origins of modern natural sciences explained]. Amsterdam: Bert Bakker.

Collier, A. 1994. Critical Realism: An Introduction to Roy Bhaskar's Philosophy. London: Verso.

Darwin, C. 1859. On the Origin of Species. London: John Murray.

De Laplace, P.-S. 1886. Euvres complètes. Paris: Gauthiers-Villars. https://iris.univ-lille.fr/ handle/1908/4943.

Dick, S. J. 2001. Life on Other Worlds: The 20th-Century Extraterrestrial Life Debate. Cambridge: Cambridge University Press. 
Feynman, R. 1977. The Feynman Lectures on Physics I. Reading, MA: Addison-Wesley Publishing Company.

Feynman, R. 1987. The Character of Physical Law. Cambridge, MA: MIT Press.

Friedman, M. 1999. Reconsidering Logical Positivism. Cambridge: Cambridge University Press.

Gerth, H. H., and C. Wright Mills. 1958. From Max Weber: Essays in Sociology. New York: Oxford University Press.

Giddens, A. 1971. Capitalism and Modern Social Theory: An Analysis of the Writings of Marx, Durkheim and Max Weber. Cambridge: Cambridge University Press.

Gollobin, I. 1986. Dialectical Materialism: Its Laws, Categories, and Practice. New York: Petras Press.

Habermas, J. 1981. Theorie des Communikatives Handelns [Theory of communicative action]. Frankfurt on the Main: Suhrkamp Verlag.

Henderson, L. J. 1967. Pareto’s General Sociology: A Physiologist's Interpretation. New York: Russell \& Russell.

Herrmann, P., L. J. G. van der Maesen, and A. C. Walker. 2012. "Conceptual Location of Social Quality.” In Social Quality: From Theory to Indicators, ed. L. J. G. van der Maesen and A. C. Walker, 70-93. London: Palgrave Macmillan.

International Association on Social Quality (IASQ). 2012. Development toward Sustainability: The Need for a Comprehensive Conceptual and Methodological Framework for New Politics and Policies: A Social Quality Perspective. Working Paper no. 11. Amsterdam: IASQ. https://www.socialquality.org/ wp-content/uploads/import/2014/10/WorkingPaper-11-2012.pdf.

International Association on Social Quality (IASQ). 2019. Preliminary Ideas about the Application and Elaboration of the Social Quality Approach (SQA) in Eastern Europe: The Case of Ukraine. Working Paper no. 17. Amsterdam: IASQ. https://socialquality.org/wp-content/uploads/ IASQ-Working-Paper-17-4.pdf.

Lamarck, J. 1809. Philosophie zoologique. Paris. Dentu.

Laszlo, E. 1987. Evolution: The Grand Synthesis. Boston: New Science Library.

Lebowitz, M. A. 1973. "The Current Crisis of Economic Theory." Science \& Society 35 (11): 199214. https://www.jstor.org/stable/40401743.

Margulis, L. 1998. The Symbiotic Planet. New York: Basic Books.

Marijnissen, H. 2020. "Kabinet negeerde adviezen over pandemie aanpak" [Government ignored recommendations concerning pandemic strategy]. Trouw, 15 April. https://www.trouw.nl/zorg/ kabinet-negeerde-adviezen-over-pandemie-aanpak-be47581a/.

Martindale, D. 1960. The Nature and Types of Sociological Theory. Boston: Riverside Press.

Newton, I. 1687. Philosophiae Naturalis Principia Mathematica. London: William Dawson \& Sons.

Ollman, B. 1976. Alienation: Marx's Conception of Man in Capitalist Society. Cambridge: Cambridge University Press.

Ossowski, H. 1962. Klassenstructur im socialem Bewusstsein [Class structure in social consciousness]. Berlin: Luchterhand Verlag.

Popper, K. 1934. Logik der Forschung [Logic of research]. Tübingen: J. C. B. Mohr.

Prigogine, I. 1980. From Being to Becoming. San Francisco: Freeman and Company.

Reeves, H. 1981. Patience dans l'azur: l'Evolution cosmique [Patience in the azure: Cosmic evolution]. Paris: Éditions du Seuil.

Röd, W. 1986. Dialektische Philosophie der Neuzeit [Dialectical philosophy of modern times]. Munich: Verlag C. H. Beck.

Spinoza, B. 1678. Ethica [Ethics]. London: Dent. 
Störig, H. J. 1950. Kleine Weltgeschichte der Philosophie [Small world history of philosophy]. Stuttgart: Verlag W. Kohlhammer.

Susskind, L. 2019. Closer to Truth. Interview series. https://www.closertotruth.com/series/whats -fundamental-the-cosmos-part-1\#video-3085.

United Nations Human Settlement Programme (UN-Habitat). 2016. Slum Almanac 2015-2016: Tracking Improvement in the Lives of Slum Dwellers. Nairobi: UN-Habitat. https://unhabitat.org/ sites/default/files/download-manager-files/Slum percent20Almanac percent202015-2016_ PSUP.pdf.

Vanberg, V. 1975. Die Zwei Soziologien: Individualismus und Kollektivismus in der Sozialtheorie [The two sociologies: Individualism and collectivism in social theory]. Tübingen: J. C. B. Mohr.

Van Hal, G. 2016. Elastisch Universum [Elastic universe]. Hilversum, The Netherlands: Fontaine Uitgevers.

Van der Maesen, L. J. G. 1987. Transformatie van de Gezondheidszorg in Nederland tussen 19741987; Toepassing van vier Grondpatronen in maatschappelijke wetenschappen [Transformation of the healthcare system in The Netherlands between 1974 and 1987: Application of four ground patterns of thought in the societal sciences]. Assen, The Netherlands: Van Gorcum.

Van der Maesen, L. J. G., and A. C. Walker, eds. 2012. Social Quality: From Theory to Indicators. London: Palgrave Macmillan.

Verlinde, E. 2011. "On the Origin of Gravity and the Laws of Newton." Journal of High Energy Physics 11 (4): Article 29. doi: https://doi.org/10.1007/JHEP04(2011)029.

Weinberg, S. 1979. The First Three Minutes. New York: Basic Books.

Wheeler, J. A. 1989. "Information, Physics, Quantum: The Search for Links." In Proceedings of the 3rd International Symposium on the Foundations of Quantum Mechanics, H. Ezawa, S. I. Kobayashi, and Y. Murayama, 354-368. Tokyo: Physics Society of Japan. https://jawarchive .files.wordpress.com/2012/03/informationquantumphysics.pdf. 